\title{
Probing underlying mechanisms for PCBN tool decay during friction stir welding of nickel-based alloys
}

\author{
Buchibabu Vicharapu ${ }^{1,2}$ \\ Guilherme Vieira Braga Lemos $3,4 *$ (1) \\ Luciano Bergmann ${ }^{3}$ \\ Jorge Fernandez dos Santos ${ }^{3}$ \\ Amitava De ${ }^{2}$ \\ Thomas Clarke ${ }^{4}$
}

\begin{abstract}
Friction stir welding (FSW) of nickel-based alloys can provide joints with improved corrosion resistance and mechanical properties that are deteriorated significantly during fusion welding of these alloys. However, rapid wear and poor longevity of tools are major concerns for FSW of nickel-based alloys. Polycrystalline cubic Boron Nitride (pcBN) has emerged as an alternative tool material due to its enhanced strength and stiffness but its use for FSW of nickel-based alloys is rarely explored. An investigation is therefore undertaken to examine FSW of Inconel 625, which is a commonly used nickel-based alloy, by experimental investigation and computational process modelling. The potential failure mechanisms of pcBN tools during FSW of Inconel 625 are examined. The results showed that the thermal softening of the tungstenrhenium binder phase and dissolution of tungsten into Inconel 625 are potential mechanisms to early wear and failure of the pcBN tools for FSW of Inconel 625.
\end{abstract}

Keywords: Friction stir welding; Inconel 625; pcBN; W-Re; Peak temperature; Tool wear.

\section{Introduction}

Nickel-based alloys find wide application in aerospace, nuclear, chemical and marine industries due to high tensile strength and corrosion resistance at elevated temperature [1,2]. However, poor weldability (with fusion based welding techniques) and machinability of these alloys impose limitations on their usage for the intended parts and components $[1,3]$. For example, the machinability of nickelbased alloys is hampered due to high temperature along the tool-chip interface and aging of cutting tools [4]. Table 1 summarizes the typical wear mechanisms and tool failure modes during machining of nickel alloys, which provide a prior basis to examine FSW of these alloys [5-7].

Segregation of alloying elements, weld bead cracks and joint porosity are common problems in fusion welds of nickel-based alloys [1,8]. FSW of these alloys is a potential recourse since fusion is normally avoided [1,9]. Initial attempts to apply FSW to nickel-based alloys led to reports of rapid wear and fracture of the tool during welding $[10,11]$. Use of harder tools such as tungsten carbide (WC), polycrystalline cubic Boron Nitride ( $\mathrm{pcBN}$ ) and iridium led to limited success regarding tool longevity [1,9]. A systematic investigation is thus needed to examine the potential failure mechanisms of tools for FSW of nickel-based alloys.

Tables 2 and 3 show reported parameters and tool materials used in FSW of high strength and high temperature alloys [12-27]. Tungsten-based tools exhibited rapid wear in FSW of several different alloys (refer Table 2). Barnes et al. [17] attributed high temperature in the stir zone to rapid wear of W-Re tools. Wang et al. [20] provided similar observations in FSW of titanium alloys with tools of tungsten-based alloys. Steuwer et al. [18] compared the wear behavior of W-Re and pcBN tools in FSW of $6.35 \mathrm{~mm}$ thick HSLA-65 steels. Although the pcBN tools showed greater wear resistance and longevity compared to the W-Re tools, the former failed beyond a certain temperature even at low forces [9,17]. Miyazawa et al. [16] studied the performance of pcBN and Iridium (Ir) tools in FSW of $2.0 \mathrm{~mm}$ thick AISI 304 stainless steel (SS) plates. The Iridium tools exhibited lesser wear and greater longevity compared to the pcBN tools. Park et al. [27] and Hanke et al. [24] reported rapid

${ }^{I}$ Indian Institute of Technology Palakkad, India

${ }^{2}$ Indian Institute of Technology Bombay, India

${ }^{3}$ Helmholtz-Zentrum Geesthacht (HZG), Institute of Materials Mechanics, Solid State Materials Processing (WMP), Geesthacht, Germany

${ }^{4}$ Laboratório de Metalurgia Física - LAMEF, Programa de Pós-graduação em Engenharia de Minas, Metalúrgica e de Materiais - PPGE3M, Universidade Federal do Rio Grande do Sul-UFRGS, Porto Alegre, RS, Brasil.

*Corresponding author: guilherme.lemos@ufrgs.br

2176-1523 C 2021. Vicharapu et al. Published by ABM. This is an Open Access article distributed under the terms of the Creative Commons Attribution License, which permits unrestricted use, distribution, and reproduction in any medium, provided the original work is properly cited. 
Table 1. Wear mechanisms reported in literature during machining of nickel alloys

\begin{tabular}{ccccccc}
\hline Tool Material & $\begin{array}{c}\text { Workpiece } \\
\text { material }\end{array}$ & CS (m/min) & FR (mm/rev) & Wear mechanism & Tool failure mode & Ref \\
\hline pcBN* & Inconel 718 & $60-240$ & 0.1 & Abrasion and diffusion & binder phase softening & Shintani et al. [5] \\
pcBN & Inconel 718 & 500 & 0.35 & Abrasion & notching & Coelho et al. [6] \\
Sailon & Inconel 901 & 125 & 0.16 & Attrition & notching & Pawade et al. [7] \\
& & 245 & 0.16 & Diffusion & flank wear & \\
\hline
\end{tabular}

CS: Cutting speed; FR: Feed rate; pcBN: poly crystalline cubic Boron Nitride in which Co, TiN and TiC were utilized as different binder phases, where Co: Cobalt, TiN: Titanium nitride, TiC: Titanium carbide.

Table 2. Reported parameters and tool characteristics in FSW of various alloys

\begin{tabular}{lcccccc}
\hline Workpiece material & Th. $(\mathbf{m m})$ & $\mathbf{N}(\mathbf{r p m})$ & $\mathbf{v}(\mathbf{m m} / \mathbf{m i n})$ & Tool material & $\mathbf{T}_{\mathbf{p}}(\mathbf{K}) *$ & Ref \\
\hline 12\% Cr steel & 12 & NA & 240 & WC & NA & Thomas et al. [12] \\
AISI 1018 & 6.0 & 450 & 40 & Mo alloy & 1205 & Lienert et al. [13] \\
SAE 304 SS & 1.5 & 600 & $60-600$ & WC & $1100-1275$ & Ishikawa et al. [14] \\
SAE 304 SS & 3.0 & 285 & $53-84$ & WC & $1260-1265$ & Siddiquee and Pandey [15] \\
SAE 304 SS & 2.0 & 1080 & 400 & Ir and Ir alloy & 1250 & Miyazawa et al. [16] \\
HSLA-65 & 6.3 & 600 & $50-500$ & W-Re & $1196-1210$ & Barnes et al. [17], Steuwer et al. [18] \\
Maraging steel 250 & 5.5 & 600 & 25 & WC, W-Mo, W-Fe & 1370 & Meshram et al. [19] \\
Ti-6Al-4V & 2.5 & 900 & 50 & W-La, WC411, CY16 & $1390-1450$ & Wang et al. [20] \\
& 3.0 & 630 & $4-22$ & WC-Co & 1433 & Nasresfahani et al. [21] \\
SAE 316L SS & 3.0 & 600 & 45 & W-La ${ }_{2}$, W-Ni-Fe-Mo-Co & 1275 & Kumar et al. [22] \\
\end{tabular}

Mo: Molybdenum; W-Mo: Tungsten molybdenum; W-Fe: Tungsten-ferrous; W-Re: Tungsten-rhenium; W-La: Tungsten-lanthanum; WC-Co: Tungstencarbide-cobalt; Ir: Iridium; WC411: $(83 \% \mathrm{WC}+11 \% \mathrm{TaC}) ; \mathrm{CY} 16:(73 \% \mathrm{WC}+8 \% \mathrm{Co}+8 \% \mathrm{TiC}+8 \% \mathrm{TaC}), \mathrm{W}_{-} \mathrm{La}_{2} \mathrm{O}_{3}$. ${ }^{*}$ The procedure for analytical estimation of peak temperature $\left(\mathrm{T}_{\mathrm{P}}\right)$ is provided in Appendix I [23].

Table 3. Reported parameters of FSW of various alloys with pcBN tools

\begin{tabular}{|c|c|c|c|c|c|}
\hline Workpiece & Th. (mm) & N (rpm) & $\mathrm{v}(\mathrm{mm} / \mathrm{min})$ & $\mathbf{T}_{\mathrm{P}}(\mathrm{K})$ & Ref \\
\hline Inconel 625 & 3.2 & 180 & 60 & 1230 & Hanke et al. [24] \\
\hline Inconel 600 & 4.8 & 600 & 60 & 1476 & Sato et al. [25] \\
\hline $\mathrm{Cp}-\mathrm{Ti}$ & 2.0 & 200 & 50 & 1383 & Zhang et al. [26] \\
\hline SAE $304 \mathrm{SS}$ & 4.5 & 550 & 80 & 1466 & Park et al. [27] \\
\hline SAE $304 \mathrm{SS}$ & 2.0 & 1080 & 400 & 1356 & Miyazawa et al. [16] \\
\hline HSLA-65 & 6.3 & 400 & $50-500$ & 1214 & Barnes et al. [17], Steuwer et al. [18] \\
\hline
\end{tabular}

$\mathrm{T}_{\mathrm{P}}$ is estimated analytically as per ref [23]. to obtain an order of estimate for a rational comparison.

wear of pcBN tool in FSW of AISI 304 SS and Inconel 625 , respectively, and attributed the same to high peak temperature. Similar observations were also reported in high speed machining of nickel alloys by pcBN tool [28].

In this work, a detailed investigation on FSW of nickel-based alloys using pcBN tools is undertaken with a focus to examine the potential degradation mechanisms of the tools by experimental investigation and computational process modelling. In particular, the computed results of peak temperature, thermal cycles, torque and traverse force, and the mechanical stresses experienced by the tool are used to inquire their relative effects on the wear and failure of the pcBN tools for FSW of Inconel 625.

\section{Experimental procedure}

Inconel 625 sheets in sizes of $500 \mathrm{~mm} \times 150 \mathrm{~mm} \times$ $3.2 \mathrm{~mm}$ are joined in butt joint configuration on a custom- made FSW Gantry machine fitted with servomotors, data acquisition instrumentations, and control systems. The pcBN tools were obtained under the Q70 specification from MegaStir $\mathbb{C}$. These Q70 type tools consisted of $70 \%$ $\mathrm{cBN}$ and $30 \% \mathrm{~W}-\mathrm{Re}$ (both in wt $\%$ ) with the latter serving as the binder. Table 4 presents the dimensions of the tool and workpiece, and welding conditions considered in the current study [29]. Type-K thermocouples with thermal sheathing were used for monitoring of thermal cycles at six pre-determined locations during the FSW experiments as shown in Figure 1. All the thermal cycles were measured at a sampling rate of $10 \mathrm{~Hz}$. The tool torque, axial force and traverse force were measured simultaneously using the machine tool dynamometer at a sampling rate of $50 \mathrm{~Hz}$. Scanning electron microscopy (SEM) and energy dispersive $\mathrm{X}$-ray spectroscopy (EDS) analysis were carried out to examine the traces of particles from the pcBN tool in the stir zone (SZ) of the welds. At each welding condition, EDS 
Table 4. Tool and workpiece dimensions (in $\mathrm{mm}$ ) considered in each configuration

\begin{tabular}{|c|c|c|c|c|c|c|c|c|}
\hline \multirow{2}{*}{ Work-piecece } & \multicolumn{5}{|c|}{ Tool } & \multicolumn{3}{|c|}{ Weld parameters } \\
\hline & & SD & PDR & PDT & PL & $\mathbf{N}(\mathbf{r p m})$ & $\mathrm{v}(\mathbf{m m} / \mathbf{s})$ & Th \\
\hline Inconel 625 & pcBN & 26.3 & 10.2 & 8.4 & 2.8 & $200,1000,1200$ & $1.0,1.5$ & 3.2 \\
\hline Inconel 600 & $\mathrm{WC}$ & 15.0 & 6.0 & 6.0 & 1.8 & 400 & $3.34,4.15$ & 2.0 \\
\hline
\end{tabular}

SD: Shoulder diameter; PDR: probe diameter at root; PDT: probe diameter at tip; PL: probe length; N: Tool rotation speed; v: Welding speed; Th: thickness.

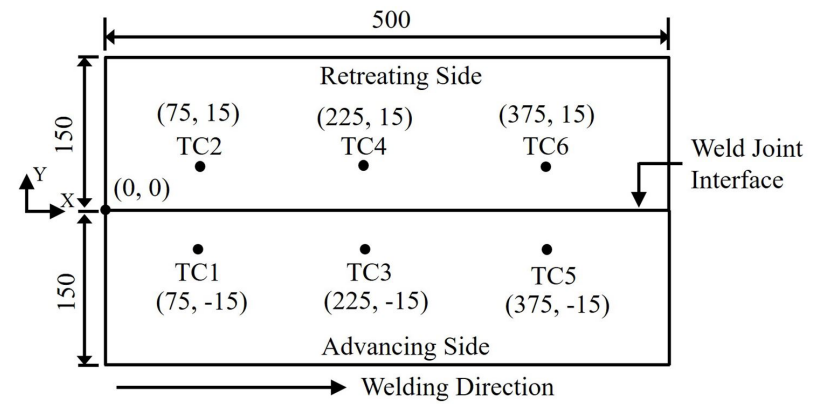

Figure 1. Configuration of the welded test piece and locations of thermocouples [TC1 to TC6] that were placed $0.5 \mathrm{~mm}$ below the top surface. All dimensions in $\mathrm{mm}$.

measurements were taken at seven different locations in the top surface of the joints.

\section{Numerical modelling}

A steady state three-dimensional heat conduction analysis was undertaken to estimate the temperature field following the governing equation as [30,31] (Equation 1).

$$
\frac{\partial}{\partial x}\left(k \frac{\partial T}{\partial x}\right)+\frac{\partial}{\partial y}\left(k \frac{\partial T}{\partial y}\right)+\frac{\partial}{\partial z}\left(k \frac{\partial T}{\partial z}\right)+\dot{Q}=\rho C_{P} v \frac{\partial T}{\partial x}
$$

where $\rho, k, C_{\mathrm{p}}$ and $\mathrm{v}$ refer to the density, thermal conductivity, specific heat, and welding speed, respectively. The heat transfer analysis was conducted using the finite element software ABAQUS (6.8EF-1 version) [32]. Figure 2 presents the solution domain with the blue color outline and the region indicating respectively the tool shoulder diameter and the tool probe. The rate of heat generation $(\dot{Q})$ along the tool and workpiece interface is estimated analytically as [30,33] (Equation 2).

$$
\dot{Q}=\eta_{h}\left[\eta_{m}(1-\delta) \tau_{y}+\delta \mu_{f} P_{N}\right](\omega r-v \sin \theta)\left(A_{i} / V_{i}\right)
$$

where $\eta_{\mathrm{m}}$ and $\eta_{\mathrm{h}}$ are the fractional mechanical work due to sticking friction converted to heat and the fraction of total heat transfered to workpiece, respectively; $r$ and $\theta$ are the radial distance of a point from the tool axis and its orientation with the welding direction; and $\mathrm{P}_{\mathrm{N}}, \omega$, and $\tau_{\mathrm{y}}$ are the axial pressure, angular speed of tool and the shear yield stress of workpiece alloy, respectively. Ai and Vi refer to the area and volume of the shear layer around the tool probe. The terms $\delta$ and $\mu_{\mathrm{f}}$ refer to the local variations in fractional sliding and co-efficient of friction along the tool - workpiece interface and are estimated as [30-33] (Equation 3 and 4).

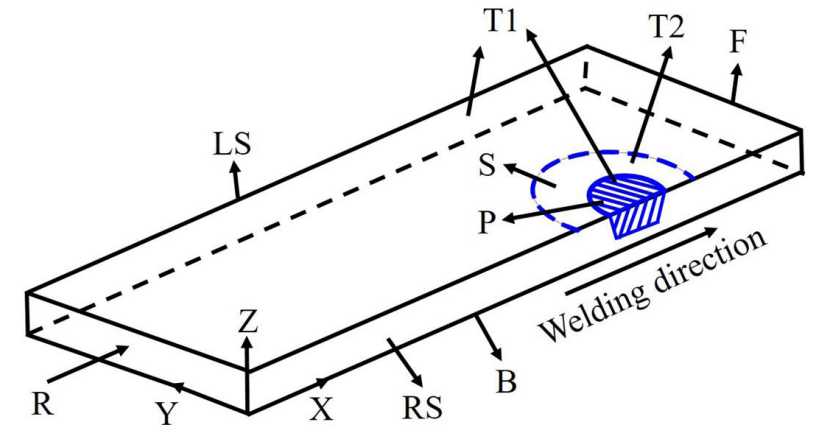

Figure 2. Solution domain considered for modeling. F, R, B, LS, RS and T1: front, rear, top left, right and top surfaces of workpiece, T2: tool shoulder surface.

Table 5. Modeling parameters

\begin{tabular}{lccc}
\hline Workpiece & $\boldsymbol{\eta}_{\mathbf{h}}$ & $\boldsymbol{\eta}_{\mathbf{m}}$ & $\mathbf{h}_{\mathbf{0}}, \mathbf{W} / \mathbf{m}^{2} \mathbf{K}$ \\
\hline Inconel 625 & 0.3 & 0.3 & 10 \\
Inconel 600 & 0.4 & 0.4 & 80 \\
\hline
\end{tabular}

$$
\delta=-0.026+0.31 \exp (r \omega / 1.87)
$$

$$
\mu_{f}=0.3 \exp (-\delta r \omega)
$$

A temperature dependent heat transfer coefficient as $h_{0} T^{1.25}$ was considered for the bottom surface (B) with $h_{0}$ as an arbitrary constant. For all other faces (F, R, LS, T1 in Figure 2) of the solution domain, a constant convective heat transfer coefficient of $10 \mathrm{~W} / \mathrm{m}^{2} \mathrm{~K}$ was applied. Table 5 shows the values of $\eta_{m}, \eta_{h}$ and $h_{0}$, which are used in the modeling calculations following published literature [30-33].

The solution domain was discretized considering threedimensional eight node brick element referred to as $D C C 3 D 8$ in $A B A Q U S$. The user-defined subroutine UMASFL was used to specify the mass flow rate ( $\rho v)$ opposite to the welding direction [30]. Table 6 shows the thermo-physical properties of the workpiece and tool materials, which are used in used in the modeling calculations. Figure 3 shows the overall scheme of work flow adopted for current study in order analyze the pcBN tool decay during FSW of nickel alloys.

\section{Results and discussion}

Figure 4 shows the computed temperature field in workpiece and tool at different tool rotational speeds and 
Table 6. Thermo-physical properties of workpiece and tool materials [T in K]

\begin{tabular}{|c|c|c|c|c|}
\hline & Inconel 625 [34] & Inconel 600 [35] & pcBN [36] & WC-Co \\
\hline$\rho\left(\mathrm{kg} / \mathrm{m}^{3}\right), \mathrm{T}_{\mathrm{S}}(\mathrm{K})$ & 8400,1563 & 8400,1563 & 3450,3246 & 7810,3143 \\
\hline $\mathrm{k}, \mathrm{W} / \mathrm{m} \mathrm{K}$ & $5.06+0.02 \mathrm{~T}$ & $9.74+0.02 \mathrm{~T}$ & 250 & 40 \\
\hline & $300 \leq \mathrm{T} \leq 1255$ & $300 \leq \mathrm{T} \leq 1073$ & & \\
\hline $\mathrm{C}_{\mathrm{P}}, \mathrm{J} / \mathrm{kg} \mathrm{K}$ & $\begin{array}{l}381.83+0.21 \mathrm{~T} \\
300 \leq \mathrm{T} \leq 1365\end{array}$ & $\begin{array}{l}381.83+0.21 \mathrm{~T} \\
300 \leq \mathrm{T} \leq 1173\end{array}$ & 1470 & 500 \\
\hline$\sigma_{\mathrm{Y}}, \mathrm{MPa}$ & \multicolumn{2}{|c|}{$\mathrm{A} 2+(\mathrm{A} 1-\mathrm{A} 2) /(1+\exp (\mathrm{T}-\mathrm{C} 3) / \mathrm{C} 4) ; 300 \leq \mathrm{T} \leq 1500$} & NA & NA \\
\hline
\end{tabular}

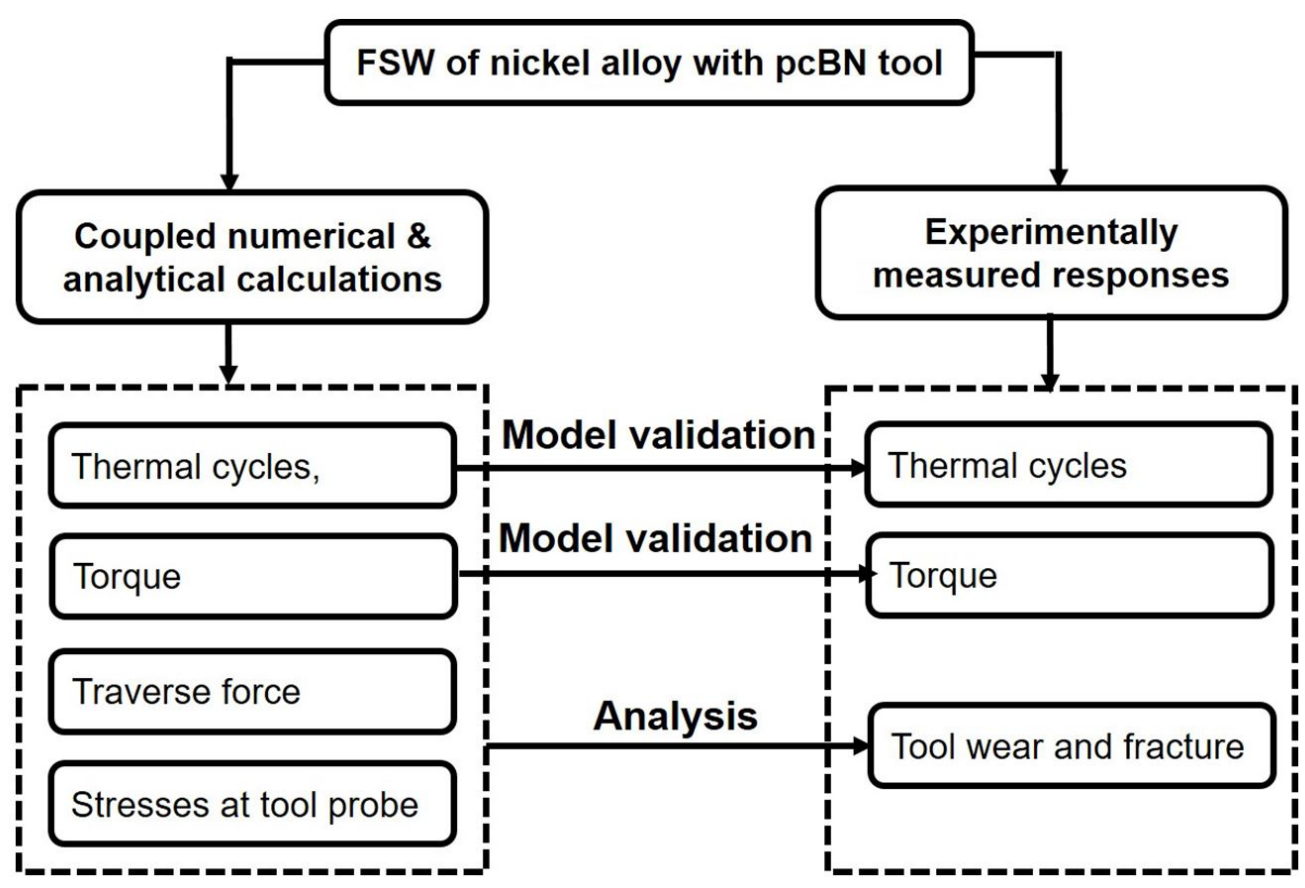

Figure 3. Experimental and numerical scheme employed for the current study.
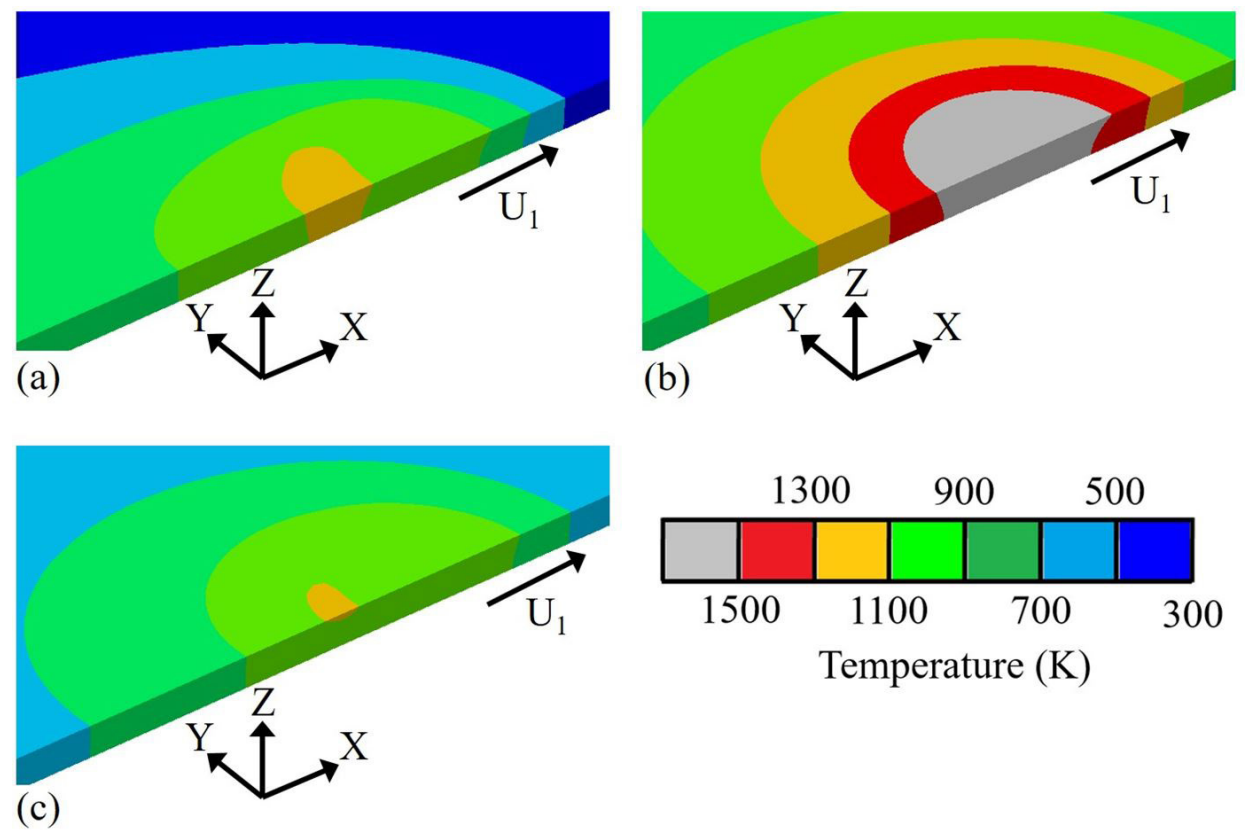

Figure 4. Computed temperature field in Inconel 625 at a tool rotational speed (rpm) and welding speed (mm/s) of (a) (200, 1.0), (b) (1200, $1.0)$, (c) $(200,1.5)$. 
welding speeds for FSW of Inconel 625. A comparison of Figures $4 \mathrm{a}$ and $4 \mathrm{~b}$ shows an increase in peak temperature from 1080 to $1550 \mathrm{~K}$ with increase in the tool rotational speed from 200 to $1200 \mathrm{rpm}$ that is attributed to greater rate of heat generation. In contrast, increase in welding speed from 1.0 to $1.5 \mathrm{~mm} / \mathrm{s}$ has led to reduced peak temperature from 1089 to $1039 \mathrm{~K}$ that is attributed to decrease in the rate of heat generation per unit length of weld with increasing welding speed (Figures 4a, 4c). Similar trends in peak temperature were also reported in literature for FSW of steels and titanium alloys [33].

Figure 5 displays a comparison of the computed and measured thermal cycles in FSW of Inconel 625 and Inconel 600 for multiple welding conditions. Figure 5a depicts the computed and the experimentally measured thermal cycles for FSW of Inconel 625 at a tool rotational speed of $200 \mathrm{rpm}$ and welding speed of $1.0 \mathrm{~mm} / \mathrm{s}$ corresponding to the thermocouple location, TC3. Likewise, Figures $5 \mathrm{~b}$ and $5 \mathrm{c}$ show a comparison between the computed and corresponding measured thermal cycles [29] for FSW of Inconel 600 using WC-Co tools. The measured thermal cycles shown in Figures $5 \mathrm{~b}, 5 \mathrm{c}$ were taken from [29] in which the thermocouple was located at the original weld centerline and at the bottom of the workpiece. The experimentally measured thermal cycles are used here to validate model results. The maximum error between the computed and corresponding measured thermal cycles remained around $2 \%$ to $6 \%$ only.

The computed temperature field was used further to estimate the torque and traverse force in FSW of Inconel 625. The values of torque, traverse force and resultant mechanical stresses on the tool probe were estimated using the principles of solid mechanics and presented in Table 7 [30]. For the process conditions considered, the estimated values of torque, traverse force and shear stresses on the tool probe are found to be in the range of 24 to $113 \mathrm{Nm}, 2.1$ to $4.8 \mathrm{kN}$, and 101 to $127 \mathrm{MPa}$. As the peak temperature reduced from 1549 to $1080 \mathrm{~K}$ with increase in tool rotational speed, the tool probe was required to travel through colder and stronger workpiece material resulting in higher values of torque, traverse force and shear stresses on the tool probe (Table 7).

Figure 6 shows the micrographs of the stir zone top surface of the welded sheets of Inconel 625 at different combinations of welding speed and tool rotational speeds. The measured EDS locations in the SZ at different welding conditions are highlighted with red color circles in Figures 6b-e and the $\mathrm{W}$ content by EDS is presented in Table 8 . Since the original chemical composition of Inconel 625 precludes any presence of $\mathrm{W}$, it is reasonable to assume that this element (W) has come from the interaction between the pcBN tool and the workpiece. The dark particles in Figure 6a can be carbides in the SZ at the highest tool rotational speed (1200 rpm). In addition, the welds made at high tool rotational speeds (Figure 6b, 6c) indicated an increased tool wear due to the greater quantities of $\mathrm{W}$ along the stir zone (Table 8). These welds also suffered from the local heterogeneities in the stir zone. In contrast, the welds made at lower tool rotational speeds (Figures 6d, 6e) depicted lower W content on their stir zone (see Table 8). These welds depicted a relatively more homogeneous structure with traces of the binder phase (from pcBN tool). Finally, these clearly indicate the disintegration of the pcBN tool and is also manifested
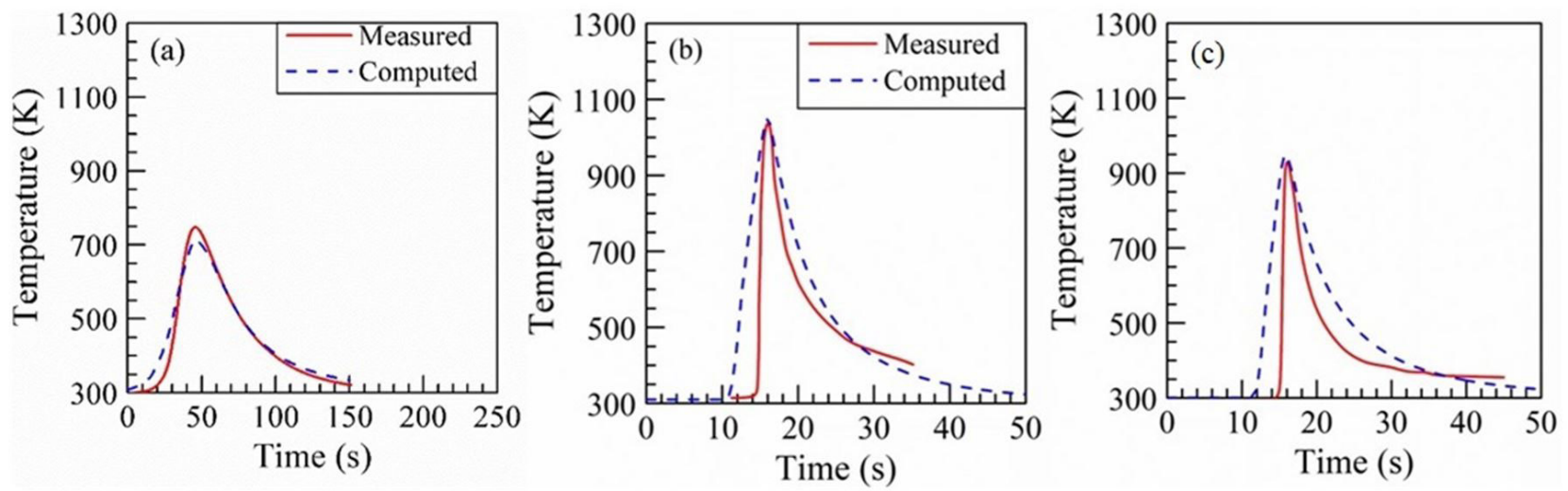

Figure 5. Computed and corresponding measured thermal cycles in FSW of (a) Inconel 625 and (b, c) Inconel 600 . The tool rotational speed $(\mathrm{rpm})$ and welding speed (mm/s) were (a) $(200,1.0)$, (b) (400, 3.34), and (c) (400, 4.15). Table 4 show details of tool and workpiece.

Table 7. Peak temperature $\left(\mathrm{T}_{\mathrm{p}}\right)$ (computed), tool torque $(\mathrm{M})$ (measured and estimated), traverse force (F) (estimated), and maximum resultant stress $\left(\tau_{\mathrm{M}}\right)$ (estimated) on tool probe in FSW of $3.2 \mathrm{~mm}$ thick Inconel 625.

\begin{tabular}{|c|c|c|c|c|c|c|}
\hline \multirow{2}{*}{ N (rpm) } & \multirow{2}{*}{$\mathbf{v}(\mathbf{m m} / \mathbf{s})$} & \multicolumn{2}{|c|}{ M (Nm) } & \multirow{2}{*}{$F(k N)$} & \multirow{2}{*}{$\mathbf{T}_{\mathrm{P}}(\mathbf{K})$} & \multirow{2}{*}{$\tau_{\mathrm{M}}(\mathrm{MPa})$} \\
\hline & & Meas. & Est. & & & \\
\hline 200 & 1.0 & $110 \pm 5$ & 113 & 4.9 & 1080 & 111 \\
\hline 200 & 1.5 & $121 \pm 6$ & 127 & 5.6 & 1039 & 127 \\
\hline 1000 & 1.0 & $30 \pm 2$ & 36 & 2.8 & 1421 & 104 \\
\hline 1200 & 1.0 & $25 \pm 1$ & 24 & 2.1 & 1549 & 101 \\
\hline
\end{tabular}



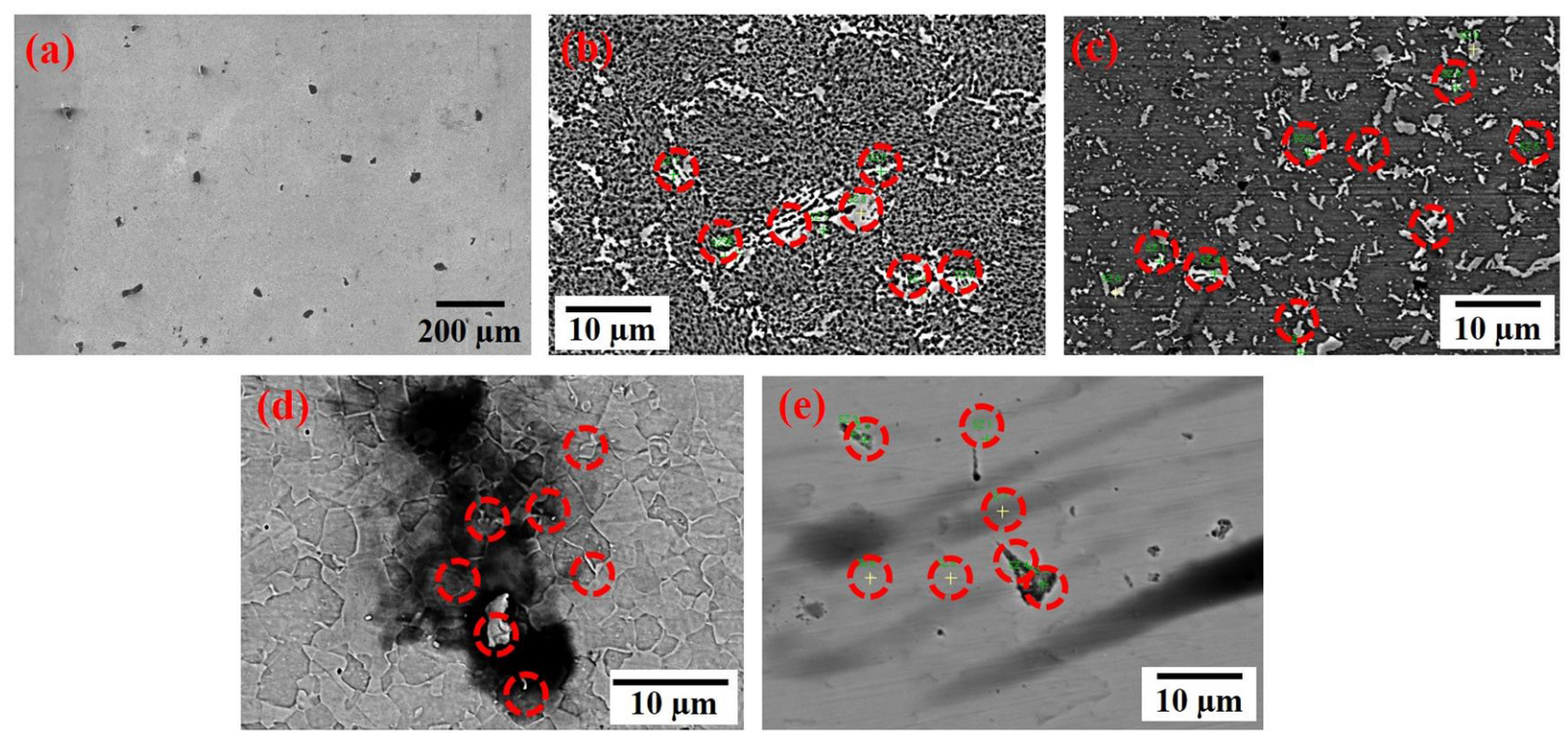

Figure 6. Stir zone microstructures at different combinations of tool rotational speeds (rpm) and welding speeds (mm/s): (a, b) (1200, 1.0), (c) $(1000,1.0),(d)(200,1.0)$ and (e) $(200,1.5)$ in FSW of $3.2 \mathrm{~mm}$ thick Inconel 625.

Table 8. Measured mass percentage of tungsten by EDS at different locations shown in Figure $6 \mathrm{~b}-\mathrm{d}$ at different welding speeds (mm/s) and tool rotational speeds (rpm) in FSW of $3.2 \mathrm{~mm}$ thick Inconel 625

\begin{tabular}{ccccc}
\hline \multirow{2}{*}{ Measured Location } & & $\mathbf{1 . 0} \mathbf{~ m m} / \mathbf{s}$ & & $\mathbf{1 . 5} \mathbf{~ m m} / \mathbf{s}$ \\
\cline { 2 - 5 } & $\mathbf{1 2 0 0} \mathbf{~ r p m}$ & $\mathbf{1 0 0 0} \mathbf{~ p m}$ & $\mathbf{2 0 0} \mathbf{~ p m}$ & $\mathbf{2 0 0} \mathbf{~ r p m}$ \\
\hline 1 & 1.95 & 1.73 & 0.09 & 0.49 \\
2 & 0.97 & 1.56 & 0.16 & 0.38 \\
3 & 1.22 & 1.78 & 0.61 & 0.56 \\
4 & 0.66 & 2.26 & 0.26 & 0.02 \\
5 & 0.86 & 1.79 & 0.01 & 0.61 \\
6 & 0.34 & 1.61 & 0.33 & 0.02 \\
7 & 1.58 & 1.87 & $\mathbf{0 . 2 7}$ & $\mathbf{0 . 3 8}$ \\
\hline Avg. & $\mathbf{1 . 0 9}$ & $\mathbf{1 . 8 0}$ & & \\
\hline
\end{tabular}

by its fragments presented on the top surfaces of the stir zones as shown in Figure 6.

The reported peak temperature in Table 7 at a tool rotational speed of $1200 \mathrm{rpm}$ is $1549 \mathrm{~K}$. This observation corroborated well with our earlier experimental based publication [24]. The higher tungsten content in the welds, which is observed for welds at higher tool rotational speeds, is attributed to the thermal softening of the W-Re binder phase and diffusion of tungsten from the tool into the stir zone at high temperatures $(>1373 \mathrm{~K})$. An increasing tendency of tungsten to diffuse into nickel substrates at around $1373 \mathrm{~K}$ or above is documented in [37]. The little presence of tungsten in the stir zone of the weld at lower tool rotational speed is attributed to mechanical wear and fracture of the tool as it experiences stronger substrate material.

Lemos et al. [1] and Hanke et al. [24] also showed that pcBN tools suffered lesser wear during FSW of Inconel 625 at lower welding speeds and tool rotational speeds in comparison to that at much higher tool rotational speeds. This can be corroborated further by considering that the shear yield strength of pcBN at around $1000 \mathrm{~K}$ is approximately
$1730 \mathrm{MPa}$, which is higher than the estimated shear stresses on the tool probe in Table 7 [38]. It appears therefore unlikely that the pcBN tool probe would fail by shear fracture. Similar calculations of the resultant shear stress on $\mathrm{pcBN}$ tool probe in FSW of nickel, steel and titanium alloys (Tables 2 and 3) also indicate that the resultant mechanical stresses are lower than the shear yield strength of pcBN material.

Hartman et al. [39] recently reported that the pcBN tool wear is dominated by the $\mathrm{BN}$ pullouts in friction stir spot welding (FSSW) of DP980 Steel. The rhenium additions above $20 \%$ by weight precipitates sigma phase along the grain boundaries when the W-Re tool cools to room temperature after welding. Sigma phase is extremely harder (1300-2000 Hv) and brittle [40]. Ratschbacher and Luidold [41] noticed higher rate of oxidation in tungstenrhenium (W-Re) alloy in comparison with the pure tungsten (W) above $1073 \mathrm{~K}$. Recently, Michel [42] showed the grain pullouts from the W-Re tool in FSW of X70 pipeline steel. All these above mentioned studies highlighted that W-Re binder phase tends to become weaker, and cBN grains are likely to disintegrate from the tool matrix above $1073 \mathrm{~K}$. 
Almoussawi and Smith [36] argued that softening of the W-Re binder material at temperatures above $1500 \mathrm{~K}$ could be the main reason for pcBN tool wear. Their analysis considered the dwell stage of FSW with the tool moving at a constant rotational speed and at a fixed location. Hanke et al. [24] and Barnes et al. [17] found traces of dissolved tungsten (W) in the stir zones of friction stir welds in Inconel 625 and HSLA 65 indicating dissolution of W-Re binder phase from the pcBN tool. Hanke et al. [24] opined further that the diffusion of tungsten (W) from the binder phase into cubic boron nitride $(\mathrm{CBN})$ crystals at high temperature resulted in weakening of the pcBN structure and removal of CBN grains to the stir zone of welds [24]. In FSW of SAE 310 SS, Park et al. [27] found the presence of borides in the stir zone microstructure that indicated disintegration of pcBN matrix and weakening of the tool. The excess wear of tungsten carbide tools as reported in Table 2 in FSW of nickel and titanium alloys and steels also corroborated these findings.

In summary, the mechanical forces and the resultant maximum shear stress on the tool probe do not appear to be the main reason for the tool wear and fracture of the pcBN tools in FSW of Inconel 625. The incipient interaction between the W-Re binder phase of the pcBN tool matrix with Inconel 625 at higher temperatures is the primary reason for the tool wear and subsequent fracture of $\mathrm{pcBN}$ tools.

\section{Conclusions}

1. In FSW of Inconel 625 using pcBN tool, the thermal softening of W-Re binder phase and diffusion of tungsten into the stir zone are the likely mechanism for progressive wear and fracture of the tools. Elevated peak temperature of the tool due to slower welding speed and higher tool rotational speeds accelerate the tool wear;

2. The effect of mechanical stresses appears to have little impact on wear and failure of pcBN tools for FSW of nickel-based alloys. Processing conditions that can restrict the peak temperature during welding facilitates the improved longevity of pcBN tools.

\section{Acknowledgements}

Authors would like to thank CNPq (National Council for Scientific and Technological Development) through the Science Without Borders program and CAPES (Brazil) for their support (grant number 152437/2014-7). Also, we would like to acknowledge the financial support of CAPES PROBRAL- 88881.198810/2018-01.

\section{References}

1 Lemos GVB, Hanke S, Santos JF, Bergmann L, Reguly A, Strohaecker TR. Progress in friction stir welding of Ni alloys. Science and Technology of Welding and Joining. 2017;22(8):643-657.

2 Ulutan D, Ozel T. Machining induced surface integrity in titanium and nickel alloys: a review. International Journal of Machine Tools \& Manufacture. 2011;51(3):250-280.

3 Bushlya V, Gutnichenko O, Zhou J, Avdovic P, Ståhl J-E. Effects of cutting speed when turning age hardened Inconel718 with ${ }_{\mathrm{p}} \mathrm{CBN}$ tools of binder less and low-CBN grades. Machining Science and Technology. 2013;17(4):497-523.

4 Arunachalam R, Mannan MA. Machinability of nickel-based high temperature alloys. Machining Science and Technology. 2000;4(1):127-168.

5 Shintani K, Kato H, Maeda T, Fujimura Y, Yamamoto A. Cutting performance of CBN tools in machining of nickelbased super alloys. Journal of the Japan Society for Precision Engineering. 1992;58(10):1685-1690.

6 Coelho RT, Silva LR, Braghini A Jr, Bezerra AA. Some effects of cutting edge preparation and geometric modifications when turning Inconel 718TM at high cutting speeds. Journal of Materials Processing Technology. 2004;148(1):147-153.

7 Pawade RS, Joshi SS, Brahmankar PK, Rahman M. An investigation of cutting forces and surface damage in high speed turning of Inconel 718. Journal of Materials Processing Technology. 2007;192-193:139-146.

8 Avery RE, Tuthill AH. Guidelines for the welded fabrication of nickel alloys for corrosion resistant service. Toronto: Nickel Development Institute; 1994. (Book Series; no. 11 012).

9 Çam G. Friction stir welded structural materials: beyond Al-alloys. International Materials Reviews. 2011;56(1):148.

10 Rai R, De A, Bhadeshia HKDH, DebRoy T. Review: friction stir welding tools. Science and Technology of Welding and Joining. 2011;16(4):325-342. http://dx.doi.org/10.1179/1362171811Y.0000000023. 
11 Zhang YN, Cao X, Larose S, Wanjara P. Review of tools for friction stir welding and processing. Canadian Metallurgical Quarterly. 2012;51(3):250-261.

12 Thomas WM, Threadgill PL, Nicholas ED. Feasibility of friction stir welding steel. Science and Technology of Welding and Joining. 1999;4(6):365-372.

13 Lienert TJ, Stellwag WL Jr, Grimmett BB, Warke RW. Friction stir welding studies on mild steel. Welding Journal. 2003;82:1S-9S.

14 Ishikawa T, Fujii H, Genchi K, Iwaki S, Matsuoka S, Nogi K. High speed-high quality friction stir welding of austenitic stainless steel. ISIJ International. 2009;49(6):897-901.

15 Siddiquee AN, Pandey S. Experimental investigation on deformation and wear of WC tool during friction stir welding of stainless steel. International Journal of Advanced Manufacturing Technology. 2014;73(1-4):479-486.

16 Miyazawa T, Iwamoto Y, Maruko T, Fujii H. Development of high strength Ir based alloy tool for friction stir welding. Science and Technology of Welding and Joining. 2012;17(3):213-218.

17 Barnes SJ, Bhatti AR, Steuwer A, Johnson R, Altenkirch J, Withers PJ. Friction Stir Welding in HSLA-65 Steel: Part I. The influence of weld speed and tool material on microstructure development. Metallurgical and Materials Transactions. A, Physical Metallurgy and Materials Science. 2012;43A:2042-2055.

18 Steuwer A, Barnes SJ, Altenkirch J, Johnson R, Withers PJ. Friction Stir Welding in HSLA-65 Steel: Part II. The Influence of weld speed and tool material on the residual stress distribution and tool wear. Metallurgical and Materials Transactions. A, Physical Metallurgy and Materials Science. 2012;43A:2056-2065.

19 Meshram S, Reddy GM, Pandey S. Friction stir welding of maraging steel (Grade 250). Materials \& Design. 2013;49:58-64.

20 Wang J, Su J, Mishra RS, Xu R, Baumann JA. Tool wear mechanisms in friction stir welding of Ti-6Al-4V alloy. Wear. 2014;321:25-32.

21 Nasresfahani AR, Soltanipur AR, Farmanesh K, Ghasemi A. Effect of tool wear on friction stir welded joints of Ti-6Al-4V alloy. Materials Science and Technology. 2017;33(5):583-591.

22 Kumar SS, Murugan N, Ramachandran KK. Influence of tool material on mechanical and microstructure properties of friction stir welded 316L austenitic strainless steel butt joints. International Journal of Refractory Metals \& Hard Materials. 2016;56:196-205.

23 Arora A, DebRoy T, Bhadeshia HKDH. Back-of-the-envelope calculations in friction stir welding: velocities, peak temperature, torque, and hardness. Acta Materialia. 2011;99(5):2020-2028.

24 Hanke S, Lemos GVB, Bergmann L, Martinazzi D, dos Santos JF, Strohaecker TR. Degradation mechanisms of pCBN tool material during friction stir welding of Ni-base alloy 625. Wear. 2017;376-377:403-408.

25 Sato YS, Arkom P, Kokawa H, Nelson TW, Steel RJ. Effect of microstructure on properties of friction stir welded Inconel alloy 600. Materials Science and Engineering A. 2008;477(1-2):250-258.

26 Zhang Y, Sato YS, Kokawa H, Park SHC, Hirano S. Stir zone microstructure of commercial purity titanium friction stir welded using pCBN tool. Materials Science and Engineering A. 2008;488(1-2):25-30.

27 Park SHC, Sato YS, Kokawa H, Okamoto K, Hirano S, Inagaki M. Boride formation induced by pCBN tool wear in friction-stir-welded stainless steels. Metallurgical and Materials Transactions. A, Physical Metallurgy and Materials Science. 2009;40(3):625-636.

28 Zhu D, Zhang X, Ding H. Tool wear characteristics in machining of nickel-based superalloys. International Journal of Machine Tools \& Manufacture. 2013;64:60-67.

29 Song KH, Fujii H, Nakata K. Effect of welding speed on microstructural and mechanical properties of friction stir welded Inconel 600. Materials \& Design. 2009;30(10):3972-3978.

30 Buchibabu V, Reddy GM, De A. Probing torque, traverse force and tool durability in friction stir welding of aluminum alloy. Journal of Materials Processing Technology. 2017;241:86-92.

31 Vicharapu B, Liu H, Fujii H, Narasaki K, Ma N, De A. Probing residual stresses in stationary shoulder friction stir welding process. International Journal of Advanced Manufacturing Technology. 2020;106(5):1573-1586.

32 ABAQUS Inc. Abaqus analysis user's manual. Providence; 2020. Heat transfer and thermal-stress analysis [cited 2020 Aug 15]. Available at: http://130.149.89.49:2080/v6.8/books/usb/default.htm

33 Nandan R. Computational modeling of heat transfer and visco-elastic flow in friction stir welding [thesis]. Pennsylvania: The Pennsylvania State University; 2008 [cited 2020 Aug 15]. Available at: https://etda.libraries.psu. edu/files/final_submissions/5445 
34 Arif AFM, Yilbas BS. Thermal stresses developed during the laser cutting process: consideration of different materials. International Journal of Advanced Manufacturing Technology. 2008;37(7-8):698-704.

35 High Temp Metals. Inconel 600 technical data: high temperature metals. 2018 [cited 2018 Oct 10]. Available at: http://www.hightempmetals.com/techdata/hitempInconel600data.php

36 Almoussawi M, Smith AJ. Thermo-mechanical effect on polycrystalline boron nitride tool life during friction stir welding (dwell period). Metals and Materials International. 2018;24(3):560-575.

37 Allison HW, Moore GE. Diffusion of tungsten in nickel and reaction at interface with SrO. Journal of Applied Physics. 1958;29(5):842-848.

38 Harris TK, Brookes EJ, Taylor CJ. The flow stress of pCBN cutting tool materials at high temperatures. International Journal of Refractory Metals \& Hard Materials. 2001;19(4-6):267-273.

39 Hartman T, Miles MP, Hong S-T, Steel R, Kelly S. Effect of pCBN tool grade on joint strength and tool life in friction stir spot welded DP980 steel. Wear. 2015;328-329:531-536.

40 Bryskin BD, Carlén JC. Sigma phase in tungsten rhenium alloys-I. Materials and Manufacturing Processes. 1996;11(1):67-81.

41 Ratschbacher K, Luidold S. Kinetics and optimization of refractory metal alloy oxidation and sublimation. Chemieingenieurtechnik. 2015;87(11):1558-1568.

42 Michel E. The effect of tool texture and tool wear in friction stir welding of X-70 steel [thesis]. Ohio: The Ohio State University; 2013.

Received: 15 Aug. 2020

Accepted: 20 Nov. 2020 
Appendix I. Procedure for analytical estimation of peak temperature.

Procedure for analytical estimation of peak temperature reported in Tables 2 and 3. The peak temperature is estimated by the non-dimensional correlation that was proposed by Arora et al. [23]. The non-dimensional peak temperature (TND) is estimated by the corresponding non-dimensional heat input (QIN).

$$
T_{N D}=\alpha \times \log _{10}\left(Q_{I N}\right)+\beta
$$

where $\alpha$ and $\beta$ are fitting constants. The terms TND and QIN are expressed as

$$
T_{N D}=\left(T_{P}-T_{R}\right) /\left(T_{S}-T_{R}\right) ; Q_{I N}=\left(\sigma_{Y} A \omega C_{P} \varphi\right) /\left(k v^{2}\right)
$$

where TP, TR and TS are the peak, reference and solidus temperatures of the workpiece material, respectively; $\sigma \mathrm{Y}, \mathrm{A}, \omega$, $\mathrm{CP}, \Phi, \mathrm{k}$ and $\mathrm{v}$ are the yield strength of the workpiece at $0.8 \mathrm{TS}$, cross-sectional area of tool shoulder, angular velocity of tool, specific heat of workpiece, partitioning efficiency, thermal conductivity of workpiece and welding speed, respectively. The sample calculations to estimate the peak temperature is shown in Table A1.

Table A1. Sample calculation for peak temperature $\left(\mathrm{T}_{\mathrm{p}}\right)$ in FSW of AISI $304 \mathrm{SS}$

\begin{tabular}{cccccccc}
\hline Workpiece & Tool & $\mathbf{N}(\mathbf{r p m})$ & $\mathbf{v}(\mathbf{m} / \mathbf{s})$ & $\mathbf{R}(\mathbf{m})$ & $\mathbf{A}\left(\mathbf{m}^{2}\right)$ & $\mathbf{P}\left(\mathbf{k g} / \mathbf{m}^{3}\right)$ & $\mathbf{K}(\mathbf{W} / \mathbf{m ~ K})$ \\
\hline $\mathrm{SS} 304$ & $\mathrm{WC}$ & 300 & 0.0017 & 0.0095 & 0.00023 & 8000 & 23 \\
$\mathrm{Cp}(\mathrm{J} / \mathrm{kg} \mathrm{K})$ & $\sigma_{\mathrm{Y}}$ & $\Phi$ & $\mathrm{Q}_{\mathrm{IN}}$ & $\mathrm{T}_{\mathrm{ND}}$ & $\mathrm{T}_{\mathrm{R}}(\mathrm{K})$ & $\mathrm{T}_{\mathrm{S}}(\mathrm{K})$ & $\mathrm{T}_{\mathrm{P}}(\mathrm{K})$ \\
610 & 2.73 & 0.4 & $5.1 \mathrm{E} 4$ & 0.73 & 300 & 1697 & 1237 \\
\hline
\end{tabular}

